\title{
Virginia Capote Díaz/ Ángel Esteban: Escribiendo la nación, habitando España. La narrativa colombiana desde el prisma de lo transatlántico. Madrid-Frankfurt am Main: Iberoamericana/Vervuert, 2017, 268 pp. ISBN: 978-84-16922-63-5.
}

El volumen profundiza en las relaciones literarias entre España y Colombia incursionando en lo interdisciplinar. Se centra, sobre todo, en el siglo XX y principios de la nueva década, con reflexiones sobre el XIX. Su acertada organización cubre un vasto horizonte, con pertinentes reflexiones sobre el tema, en tanto permite ver cómo ha funcionado lo transatlántico a lo largo del periodo mencionado. El primer apartado, titulado Panoramas y compuesto por tres minuciosos ensayos, es un pórtico muy firme para adentrarse en los tres restantes. El segundo, Del Boom a la Generación de los cincuenta, constituye el momento crucial para dichas relaciones, a este le sigue un tercer apartado Los nuevos ecos, consagrado a autores recientes; y, finaliza con la sección dedicada a "Estudios Interdisciplinares" donde, sin dejar de estar presente lo literario, se incursiona en las relaciones históricas, sociales o políticas entre ambos países.

El primer apartado se inicia con el estudio "Tres décadas de literatura colombiana en España (1970-200o)" de la escritora y crítica colombiano-española Consuelo Triviño, protagonista de primera mano de muchas de estas vivencias; en él se lleva a cabo un penetrante análisis tanto en lo que se refiere a los procesos que se sucedieron como a los nombres emblemáticos que formaron parte de ellos; asimismo se acerca con gran pericia a los diferentes motivos por los que se produce el desplazamiento a España dependiendo de las décadas o de las ciudades: Madrid o Barcelona; las revistas en las que se dan a conocer buena parte de los intelectuales colombianos, y cómo la temática anterior se va sustituyendo a medida que avanzan las décadas.

Con el segundo texto "Lazos familiares, una estampa de una relación editorial en cinco nombres" nos situamos de nuevo en una experiencia vivida en primera persona; en él Pilar Reyes directora de la editorial Alfaguara desbroza dicho ámbito, definitivo en todo el proceso, con la eficiencia que le da su conocimiento directo; refiere los aspectos de uno de los sellos que dio mayor visibilidad a la literatura colombiana a ambos lados. Analiza los procesos que influyeron centrándose en nombres concretos (autores canónicos como Álvaro Mutis, a los que se unen nombres de gran peso como Fernando Vallejo, Juan Gabriel Vásquez, Héctor Abad Faciolince 
o Laura Restrepo). Pilar Reyes razona concienzudamente cómo Colombia fue ubicándose en el mercado editorial español, en ese sentido atiende a la llegada de grupos editoriales provenientes de España, Planeta o Alfaguara que pusieron en circulación a aquellas novelas que antes solo podían optar a editoriales colombianas como Norma, Tercer Mundo o Áncora Editores.

Esta primera parte concluye con el relevante y necesario estudio de Virginia Capote: "El papel del margen: mujeres transatlánticas y pequeñas editoriales”, cuya competencia en el tema analizado le permite bucear con gran destreza en un aspecto poco tratado. La escritura de la mujer anteriormente relegada a la periferia se ubica de este modo en el centro. Presenta un sagaz estudio sobre la mujer escritora o artista y su peripecia transatlántica y unido a ello aborda con maestría el tema de las editoriales con las que funcionaba la mujer. De acuerdo a sus palabras "se trata de completar el puzzle" y se completa con gran destreza, puzzle en el que encajan autoras como Elisa Mújica, Rocío Vélez, Sonia Truque, Anabel Torres y artistas como Enma Reyes. Con gran acierto se estudian diversas generaciones y estilos variados en Marvel Moreno, Alba Lucía Ángel o Consuelo Triviño. Se acerca no solo a su producción sino a los procesos que han seguido hasta su visibilización para pergeñar la escritura de la nación colombiana.

La segunda sección: Del Boom a la Generación de los 50, sin duda, traza el periodo de mayor envergadura para la entidad de la escritura colombiana, con la llegada del Boom la dinamización de la literatura llegó a su auge. En el artículo inicial "Crónica de una consagración literaria. Juan Gabriel Vásquez y España”, Yannelys Aparicio se acerca a la importancia que adquirió para algunos autores la figura del dictador, no sólo en García Márquez como indica su título, sino también en cómo la figura del dictador sea de Colombia o de cualquier país latinoamericano, fue esencial en el canon. A través de material de gran peso nos acercamos al proceso de creación o a los propósitos en común en relación con el mundo de los dictadores y también de la España de Franco.

Luz Mary Giraldo en "R.H. Moreno-Durán: lector que escribe" se adentra en las construcciones de Moreno Durán y, alejándolo acertadamente de la literatura testimonial o de consumo, explora con gran habilidad obras canónicas del autor como De la barbarie a la imaginación (1976) o El halcón peregrino (1995), donde rastrea variantes de la historia literaria de Latinoamérica o sus nexos con las tradiciones hispánicas a través de sus autores. Asimismo, Denominación de origen. Momentos de la literatura colombiana (1998), en la dirección anterior, ausculta las obras más reseñables de la literatura colombiana desde sus inicios. Y, sin duda, su obra El festín de los conjurados, Literatura y transgresión en el fin de siglo (2000) ofrece una ligazón con España, adquiriendo sentido los vínculos que el autor mantuvo con nuestro país. La autora no deja al margen un libro en el que el autor rinde tributo a uno de sus autores preferidos: el libro Mujeres de Babel. Voluptuosidad y frenesí verbal en Joyce (2004). El estudio es una semblanza muy pertinente de uno de los autores más significativos del XX. 
Finaliza esta sección con el pertinente artículo de Yadira Segura "Redescubrimiento de América en la novela histórica de Willian Ospina", en el que sondea de manera muy atinada la obra de Willian Ospina y su relación entre España y América. Bucea, entre otras producciones, en su imponente trilogía del Amazonas, compuesta por las novelas Ursúa (2005), El país de la canela (2008) y La serpiente sin ojos (2013) donde radica la esencia de la España de la conquista, por la que desfilan personajes bien conocidos como Pedro de Ursúa, Gonzalo Pizarro, Francisco de Orellana o Cristóbal de Aguilar y Medina. Nos situamos en lo histórico, pero también poético (en La serpiente sin ojos, hay prosa y verso). Lo asemeja, con mucho acierto, a Juan de Castellanos en su imponente Elegías de varones ilustres de indias. Además, escruta con gran tino las diferencias que marcan la diégesis de Ospina que lo acercan más a lo real que a lo ficcional.

El tercer apartado titulado Nuevos Ecos se centra en autores relativamente jóvenes, nacidos en los setenta. Jasper Vervaeke nos muestra con gran lucidez en "Crónica de una consagración literaria. Juan Gabriel Vásquez y España” los factores que contribuyeron a la coronación literaria del autor mencionado. Se estudian las relaciones editoriales que se fraguan a finales de los noventa e inicios del siglo XXI, momento neurálgico para la industria del libro y la expansión de la literatura. Dicho éxito aparece referenciado tanto en el ámbito editorial como en lo que se refiere a Premios concedidos. En este sentido, una de sus máximas consagraciones fue el Premio Alfaguara de novela otorgado en 2011 a El ruido de las cosas al caer, la última de las tres novelas escritas en Barcelona, tras Los Informantes e Historia de Costaguana, que ya había sido acreedora del Mejor Libro colombiano de Ficción, en este caso en Bogotá.

En el siguiente trabajo de esta serie, "Juan Cárdenas y la otra tradición", Catalina Quesada indaga en la obra del autor, que, si bien residió en España durante mucho tiempo, en sus obras se aparta de lo trillado y vuelve con una mirada renovada sobre la novela de la selva o sobre lo mítico, en otros casos, pero, en definitiva, miradas que se alejan de la narrativa actual. En su caso, como bien ha apuntado el autor, toma La vorágine como modelo para algunas de sus obras (es el caso de Los estratos, 2013); sin embargo, Quesada establece de manera perspicaz las distancias con la novela de la selva, que se encontrarían en "la sobriedad narrativa y la ausencia de excesos verbales". En otras novelas (Ornamento, 2015) se ubica la Colombia actual, abordando temas como la droga, el sicariato, el capitalismo y sus efectos; sin embargo, de nuevo nos alejamos de realismos manidos y nos ubicamos en discursos que lo insertan en algunos casos en lo neobarroco. Se explora el mundo y las tácticas de Cárdenas, así como los personajes en los que se focaliza estableciendo también un contrapunto con la tradición.

El apartado último presenta tres trabajos, distintos en apariencia, sin embargo, enlazados a través de las disciplinas que los recorren. En el primero de ellos, Andrea Candelo da cabida al siglo XIX con "La imagen de España en Viajes de un colombiano por Europa y el Ensayo sobre las revoluciones políticas de José María Samper” y se instala 
en un autor y un tema de gran relevancia en ese momento. Dicho tema son las impresiones de viaje por Europa o España, Samper nos ofrece una estampa múltiple de España, que escruta en todas sus regiones su administración y aspectos variados. Todo ello con el detenimiento necesario para dar claves de su estancamiento o de su relación con otros países. El anhelo del viajero, mostrado aquí con gran acierto por Candelo, es el acercamiento a España para, a través de su mirada, evidenciar de dónde procede el rezago de América Latina y también la necesidad de apartarse de ese modelo para el progreso de su lugar de origen. Se plantean muchos temas en este pertinente estudio, entre ellos el tema de la raza en el Ensayo sobre las relaciones Políticas.

Jannet Español Casallas, en "La memoria del crimen. Afinidades y diferencias en la poética de Laura Restrepo y Rafael Chirbes”, se centra en dos autores de la misma generación, pero de ámbitos geográficos diferentes: Laura Restrepo (en su obra $L a$ multitud errante) y en La buena letra del español Rafael Chirbes, autores que tienen en común acercarse a la memoria soterrada, en componer un discurso a contracorriente al hegemónico, ese que trata de borrar las huellas de la "desaparición" o del crimen. Español Casallas se enfrenta con lucidez a una tarea de convergencias y distinciones en dos autores con realidades distintas, pero formas muy similares de comprometerse con la memoria, la "desaparición forzosa”, ya sea a causa del "Bogotazo" o de la represión antifranquista, valiéndose en su análisis de los discursos de Reyes Mate o del filósofo italiano Giorgio Agamben (que a su vez toma la autoridad de Primo Levi).

Para terminar esta serie, Fernando Díaz Ruiz en el artículo "España, ¿madre o madrastra? El despecho de seis escritores colombianos por la imposición del visado a sus compatriotas" se hace ineludible en un volumen como este. Se habla de la lucha llevada a cabo por el mundo intelectual; se nuestra con una documentación muy clara la animosidad de seis escritores colombianos bien destacados (García Márquez, Álvaro Mutis, Fernando Vallejo, Willian Ospina, Darío Jaramillo Agudelo y Héctor Abad Faciolince) por la imposición del visado a sus compatriotas en 2001 tras una notificación de la Ley de Extranjería. Se evidencia con gran exactitud la reacción de rechazo de muchos intelectuales españoles. Se trata de un artículo que muestra la rotundidad con la que se luchó para reparar una injusticia; asimismo es de gran valor el detalle con el que se manifiesta todo el proceso.

En definitiva, el libro Escribiendo la nación, habitando España. La narrativa colombiana desde el prisma transatlántico viene a llenar un gran vacío en un tema de gran actualidad y necesario dentro de esta disciplina. Acercarse al país que fue tan significativo en el momento del Boom marca una nueva forma de ver la nación y las relaciones con España.

La forma eficaz en la que está organizado, en las diferentes secciones, aporta una gran información necesaria y constituye una fuente primordial para especialistas, pero también un valioso testimonio para iniciados que puedan de este modo entender de manera profunda y especializada muchos de los entramados esenciales que han tenido lugar en el periodo abarcado. 
En consonancia con lo anterior, los críticos elegidos, versados en sus respectivos campos, auscultan las realidades, las proyecciones o las estrategias literarias de autores conocidos y otros que quizás no lo sean tanto, pero que, a partir de ahora, formarán parte de los estudios de la historiografía colombiana y de sus relaciones con España.

\section{Eva Guerrero Guerrero}

Universidad de Salamanca

evaguerr@usal.es 